\title{
ORgANIZAÇÃo dO PROCESSO ENSINO-APRENDIZAGEM COM O USO DO SMARTPHONE NA PERSPECTIVA DA TEORIA DA ATIVIDADE DE ESTUDO
}

\author{
ORGANIZATION OF THE TEACHING-LEARNING PROCESS WITH THE USE OF THE \\ SMARTPHONE ON THE PERSPECTIVE OF THE THEORY OF THE STUDY ACTIVITY \\ ORGANIZACIÓN DEL PROCESO ENSEÑANZA-APRENDIZAJE CON EL USO DEL \\ SMARTPHONE EN LA PERSPECTIVA DE LA TEORÍA DE LA ACTIVIDAD DE ESTUDIO

\begin{abstract}
Elson de Paula
Marilene Ribeiro Resende ${ }^{2}$

RESUMO: As tecnologias digitais estão presentes nas atividades diárias do homem contemporâneo, principalmente entre os jovens que as utilizam com destreza e naturalidade. Neste relato de experiência, apresenta-se parte dos resultados de uma pesquisa de mestrado que teve como objetivo organizar o processo ensino-aprendizagem com o uso do smartphone numa disciplina de um curso técnico integrado ao ensino médio, na perspectiva da Teoria da Atividade de Estudo de Davidov. Essa teoria está apoiada na Teoria HistóricoCultural de Vigotski e na Teoria da Atividade de Leontiev. Utilizou-se a metodologia do experimento didático, uma intervenção pedagógica, que tem como objetivo promover aprendizagens e desenvolvimento do aluno. $\mathrm{O}$ experimento foi organizado em quatro atividades de estudo, realizadas em 18,5 horas, aproximadamente, num período de três meses. Os participantes foram 14 alunos, com idades de 16 e 17 anos. Foi possível constatar que há indícios de que o estudo organizado nessa perspectiva, usando o smartphone, despertou o querer aprender, promoveu a apropriação dos conceitos essenciais e dos processos técnicos da disciplina, desenvolvendo o pensamento teórico e promoveu a colaboração.
\end{abstract}

PALAVRAS-ChAVE: Processo ensino-aprendizagem. Didática experimental. Tecnologia educacional.

ABSTRACT: Digital technologies are present in the daily activities of contemporary man, especially among young people who use them with dexterity and naturalness. In this experience report, part of the results of a master's research that aims to organize the teaching-learning process with the use of the smartphone in a subject of a technical course integrated to high school, from the perspective of the Theory of Study Activity of Davidov. This theory is based on Vigotski's Historical-Cultural Theory and Leontiev's Theory of Activity. The methodology of the didactic experiment was used, a pedagogical intervention coherent with this theoretical approach, which aims to promote student learning and development. The experiment was organized in four study activities, carried out in 18.5 hours, approximately, in a period of three months. The participants were 14 students, aged 16 and 17 years. It was possible to verify that there is evidence that the study organized in this perspective, using the smartphone, aroused the desire to learn, promoted the appropriation of the essential concepts and technical processes of the discipline, developing theoretical thinking and promoted collaboration.

KEYWORDS: Teaching-learning process. Didactic experiment. Educational technology.

RESUMEN: Las tecnologías digitales están presentes en las actividades diarias del hombre contemporáneo, principalmente entre los jóvenes que las utilizan con destreza y naturalidad. En este relato de experiencia se presenta parte de los resultados de una investigación de maestría que tuvo como objetivo organizar el proceso enseñanza-aprendizaje con el uso del smartphone en una disciplina de un curso técnico integrado a la enseñanza media, en la perspectiva de la Teoría de la Actividad de Estudio de Davidov, apoyada en la Teoría Histórico-

\footnotetext{
${ }^{1}$ Submetido em: 16/04/2018 - Aceito em: 02/05/2018 - Publicado em: 11/01/2019
}

\begin{tabular}{l|l|l|l|l|l|l} 
(C) Rev. Educ. Perspec. & Viçosa, $M G$ & v.9 & n.2 & p.434-452 & maio/ago. 2018 & eISSN 2178-8359 \\
\hline
\end{tabular}


Cultural de Vigotski y en la Teoría de la Actividad de Leontiev. Se utilizó la metodología del experimento didáctico, una intervención pedagógica coherente con ese abordaje teórico, la cual tiene como objetivo promover aprendizajes y desarrollo del alumno. El experimento fue organizado en cuatro actividades de estudio, realizadas en 18,5 horas, aproximadamente, en un período de tres meses. Los participantes fueron 14 alumnos, con edades de 16 y 17 años. Es posible constatar que hay indicios de que el estudio organizado en esa perspectiva, usando el smartphone, despertó el querer aprender, promovió la apropiación de los conceptos esenciales y de los procesos técnicos de la disciplina, desarrollando el pensamiento teórico y promovió la colaboración.

PAlABRAS ClAVE: Proceso de enseñanza-aprendizaje. Experimento didáctico. Tecnología educacional.

\section{INTRODUÇÃO}

A evolução dos dispositivos móveis trouxe possibilidades antes consideradas impossíveis, nos mais diversos campos da vida social, científica e cultural, desde as décadas finais do século XX. Existem várias pesquisas que mostram o crescimento das vendas desses equipamentos no mundo e, principalmente, no Brasil, estando eles cada vez mais presentes na vida das pessoas, especialmente na dos jovens. A título de exemplo, segundo a International Data Corporation (IDC), "depois de dois anos de queda, o mercado brasileiro de smartphones reagiu e fechou 2017 com o segundo melhor desempenho da história: no ano, foram vendidos 47.700 milhões de aparelhos, crescimento de 9,7\% em relação a 2016" (IDC, 2018, s.p.).

Num cenário contraditório, no qual se observam, por um lado, cada vez mais tecnologias digitais disponíveis e jovens conectados e, por outro, baixo rendimento escolar, atestado pelas avaliações sistêmicas nacionais e internacionais, inúmeras questões surgem para os educadores relacionadas ao como usar essa tecnologia na educação de modo a contribuir no processo de ensino e aprendizagem. Conforme aponta Relatório da Organização para a Cooperação e Desenvolvimento Económico ou Econômico (OCDE, 2016), com base em dados do Programme for International Student Assessment (Pisa) - Programa Internacional de Avaliação de Estudantes de 2012, o Brasil é o segundo país com pior nível de aprendizado, em números absolutos, e o décimo, em termos percentuais - dos 2,7 milhões de alunos de 15 anos avaliados no Brasil, 1,9 milhão tinham dificuldades em matemática básica, 1,4 milhão em leitura, e 1,5 milhão em ciências. Ao serem cruzados, os números indicam que 1.165.231 estudantes apresentavam dificuldades em tarefas básicas. Essa é uma situação preocupante para a educação nacional.

Os recursos tecnológicos, embora não sejam autônomos e a solução para todos os problemas, pois eles também possuem suas limitações, restrições de uso e implicações, fazem parte da cultura do tempo atual e não devem ser ignorados pelos educadores. A sua presença instiga o repensar sobre qual é o papel do professor nesse mundo informatizado em que há outros

\begin{tabular}{l|c|c|c|c|c|c} 
(C) Rev. Educ. Perspec. & Viçosa, $M G$ & v.9 & n.2 & p.434-452 & maio/ago. 2018 & eISSN 2178-8359 \\
\hline
\end{tabular}


elementos mediadores, especialmente num cenário de baixos índices de aprendizagem entre os jovens.

Sobre o papel do professor na organização do ensino, Rigon et al. (2010, p. 31-32) afirmam:

Nesse sentido, uma das responsabilidades do professor é organizar situações didáticas que favoreçam o desenvolvimento, no estudante, de um querer aprender, uma vez que esse não é um valor natural, mas construído historicamente. Construir o motivo de aprender é fundamentalmente uma função educativa que, diga-se de passagem, vem sendo menosprezada por grande parte dos educadores.

Neste contexto, a pesquisa apresentada tomou como objeto de estudo a organização do processo ensino-aprendizagem com o uso de smartphone, com alunos do ensino técnico integrado ao ensino médio. Os fundamentos teóricos foram buscados na Teoria da Atividade de Estudo de Davidov ${ }^{1}$ (1930-1998), cujas bases estão na Teoria Histórico-Cultural fundada por Vigotski (1896-1934) e na Teoria da Atividade de Leontiev (1903-1979).

A investigação teve como objetivo geral organizar e analisar o processo ensino e aprendizagem com o uso do smartphone em uma disciplina de um curso técnico integrado ao ensino médio, na perspectiva da Teoria da Atividade de Estudo de Davidov.

Como procedimento metodológico, utilizou-se o experimento didático, fundamentado na Teoria Histórico-Cultural. Foi desenvolvido com um grupo de 14 alunos do segundo ano do Curso Técnico em Manutenção e Suporte em Informática Integrado ao Ensino Médio, ofertado em uma instituição pública federal em Uberaba - MG, na disciplina Organização Montagem e Manutenção de Computadores (OMMC), por meio de quatro atividades de estudo, realizadas em 18,5 horas aproximadamente, num período de três meses, de setembro a dezembro de 2015, com 8 encontros de $120 \mathrm{~min}$ e outros 4 encontros de $40 \mathrm{~min}$.

Neste relato será apresentada uma dessas atividades, como também os fundamentos teóricos que conduziram a organização e a realização dessas atividades.

\section{APORTES TEÓRICOS: A TEORIA DA ATIVIDADE E A TEORIA DA ATIVIDADE DE ESTUDO DE DAVIDOV}

Alexei Nikolaevich Leontiev, psicólogo russo, um dos principais colaboradores de Vigotski, é considerado o expoente máximo da Teoria da Atividade da psicologia soviética. De acordo com Leontiev (1978, p. 130), "a consciência individual só pode existir nas condições de uma consciência social; é apropriando-se da realidade que o homem a reflete através do prisma das significações, dos conhecimentos e das significações elaboradas socialmente". Dessa

\begin{tabular}{l|l|l|l|l|l|l} 
(C) Rev. Educ. Perspec. & Viçosa, $M G$ & v.9 & n.2 & p.434-452 & maio/ago. 2018 & eISSN 2178-8359 \\
\hline
\end{tabular}


maneira, o autor explicita a centralidade da atividade humana como meio de humanização, pela apropriação das aquisições históricas da humanidade, estabelecendo uma relação entre o desenvolvimento da consciência individual e a consciência social, produto do desenvolvimento histórico.

Leontiev (1978) diz, ainda, que o homem transforma a realidade e a si mesmo através da atividade humana numa relação dialética, produzindo assim mudanças em sua psique e em sua personalidade. A atividade é o modo especificamente humano, pelo qual o homem se relaciona com o mundo. Esse processo de recriar e transformar a natureza, a sociedade e o próprio sujeito ocorre pela atividade com base na realidade objetiva mediada pela prática. É ela uma unidade molar na constituição da personalidade do homem. Um exemplo de atividade humana consciente é a atividade de estudo, pois é orientada a um objetivo definido, que deve ser conscientizado pelo aluno como sujeito da atividade, para poder interagir e transformar o objeto e transformar-se a si mesmo. "É considerada a atividade principal das crianças em idade escolar e sua função é a de propiciar a assimilação das formas de consciência social mais desenvolvidas - a ciência, a arte, a moralidade, a lei - cujas bases são os conhecimentos teóricos científicos" (LIBÂNEO; FREITAS, 2015, p. 351).

Segundo esses autores, Davidov, ao propor o ensino desenvolvimental, afirma que a sua essência é a teoria da atividade de estudo. Seu objeto, a ser posto em prática desde as séries (anos) iniciais, de modo a formar nas crianças uma atitude para o estudo, é o nível de desenvolvimento psíquico que se atinge com o aprendizado dos conhecimentos teóricos na realização das atividades de estudo. No caso desta pesquisa, em se tratando de jovens, a atividade de estudo é, também, de preparação profissional. Davidov defende que o desenvolvimento do pensamento teórico está no centro da atividade de estudo. Esse tipo de pensamento envolve a abstração e a generalização substantivas e a formação do conceito científico. Com a intervenção do professor, como organizador do processo ensinoaprendizagem, o aluno poderá deduzir outras abstrações mais particulares e uni-las no objeto integral (concreto) estudado.

Assim, para Davidov, o professor precisa estar atento às questões que realmente levam ao desenvolvimento psíquico do aluno, ou seja, incluir situações-problema que exijam esclarecer as condições de origem dos objetos, descobrir sua essência (núcleo), o aspecto mais geral que o caracteriza, realizar o movimento do abstrato para o concreto, para a partir de aí deduzir as relações particulares do objeto de estudo.

$\mathrm{Na}$ atividade de estudo, estão presentes o conteúdo e o próprio sujeito como objetos, na qual o primeiro se caracteriza como um objeto de conhecimento, enquanto o segundo, como objeto interno do desenvolvimento de sua personalidade. A atividade de estudo é individual,

\begin{tabular}{l|c|c|c|c|c|c} 
(C) Rev. Educ. Perspec. & Viçosa, $M G$ & v.9 & n.2 & p.434-452 & maio/ago. 2018 & eISSN 2178-8359 \\
\hline
\end{tabular}


social e cultural, e tem como objeto a natureza, a sociedade, o homem ou a própria personalidade do sujeito que aprende.

A estrutura da atividade de estudo tem uma natureza dinâmica e funciona como um sistema integral, sendo que, na teoria de Leontiev, de acordo com Longarezi e Franco (2015, p. 104):

A atividade, originária de uma necessidade, é dirigida a um determinado objeto (que consiste no seu conteúdo); depende dos motivos - o que move o sujeito -; e é constituída por ações - que, por sua vez, dependem dos objetivos -; e são dirigidas por operações - que são os meios ou procedimentos para realizar a ação.

Pode-se verificar, então, que a atividade tem componentes que se relacionam - necessidade, objeto e motivo, componentes estruturais de orientação da atividade, e as ações e as operações, componentes de execução. Para lograr êxito na atividade de estudo, o professor precisa entender o papel de cada componente da atividade, pois essa compreensão guiará todo o planejamento dos processos de ensino-aprendizagem: preparação, execução, monitoramento e avaliação das atividades. Os meios, pelos quais as atividades se desenvolvem, são os mediadores entre objeto e os sujeitos da atividade e eles podem ser materiais (objetos e instrumentos) e meios de natureza informativa ou simbólica, como os signos, por exemplo.

A unidade fundamental da atividade de estudo para Davidov é a tarefa de estudo que tem por finalidade a transformação do próprio sujeito, transformação essa que não é possível fora das ações objetais que este realiza. De acordo com Repkin (2014, p. 89):

$\mathrm{Na}$ atividade de estudo, a pessoa, primeiro, se descobre como um agente e, nessa atividade, pela primeira vez, surge diante dela a tarefa de transformar-se num sujeito. Esse processo de desenvolvimento, de estabelecimento da pessoa como sujeito, adquire um caráter consciente e dirigido a objetivos. A atividade de estudo, neste sentido, também é um aspecto muito importante da formação da pessoa como uma personalidade.

Desse modo, a atividade de estudo só é, de fato, uma atividade, se o aluno a toma para si, como sujeito, de forma consciente, sob a orientação do professor, a quem cabe organizá-la.

\section{A METODOLOGIA E A TRAJETÓRIA METODOLÓGICA: O EXPERIMENTO DIDÁTICO E OS SEUS FUNDAMENTOS TEÓRICOS}

Este relato, ao apoiar-se na Teoria da Atividade de Estudo, tem como método o materialismo histórico dialético, no qual o sujeito que conhece tem um papel ativo, que não fica restrito à aparência, mas busca a essência, a apreensão do objeto como um processo, no movimento mesmo, em sua estrutura e dinâmica. Trata-se, portanto, de um processo histórico, calcado nos modos como os homens produzem a sua vida material, os seus meios de vida. Seu

\begin{tabular}{l|l|l|l|l|l|l} 
(C) Rev. Educ. Perspec. & Viçosa, $M G$ & v.9 & n.2 & p.434-452 & maio/ago. 2018 & eISSN 2178-8359 \\
\hline
\end{tabular}


método supõe sucessivas aproximações do objeto, que ampliam as determinações do objeto, portanto as sínteses produzidas a partir delas. Desse modo, pode-se afirmar que é uma pesquisa de abordagem qualitativa, na qual o processo e seu significado são os focos principais de abordagem.

Do ponto de vista de seus objetivos, trata-se de uma pesquisa explicativa, pois buscou organizar e analisar o processo ensino e aprendizagem, a partir de evidências de mudanças no pensamento dos sujeitos. No que respeita aos procedimentos é uma pesquisa experimental.

L. V. Zankov (1901-1977), psicólogo, aluno e seguidor de Vigotski, cientista da primeira geração que constituiu a Teoria Histórico-Cultural, foi o precursor do experimento didático, no que se refere ao seu planejamento e realização. Seus experimentos tinham o objetivo de provar as ideias de Vigotski sobre o ensino e desenvolvimento mental das crianças, já que se dedicou profundamente ao estudo dessa tese. Essa investigação permitiu a Zankov, segundo Aquino (2015, p. 257), elaborar várias perguntas norteadoras, entre elas, [...] "qual é o processo de desenvolvimento geral dos escolares mediante a metodologia tradicional e mediante o sistema experimental do ensino fundamental? [...]". Esses questionamentos conduziram "a ideia em que se embasou o experimento: a possibilidade de uma maior eficácia do ensino no desenvolvimento geral dos escolares" (AQUINO, 2015, p. 257).

Os experimentos didáticos desenvolvidos por Zankov, Davidov, Elkonin e outros estudiosos da psicologia soviética mostraram-se viáveis e de grande importância para melhorar o processo de ensino-aprendizagem. No Brasil, começaram a ser utilizados como metodologia de pesquisa a partir do início desse século, por pesquisadores que se alinham à perspectiva da Teoria Histórica Cultural, em questões relacionadas ao ensino-aprendizagem em diversas áreas do conhecimento.

Sobre essa metodologia de pesquisa e de ensino, Freitas (2010, p. 6) complementa, dizendo que:

O experimento didático-formativo visa analisar mudanças qualitativas no pensamento do sujeito em função de seu aprender e a partir de certo modo de ensinar. As mudanças são investigadas como processos inseparáveis do aprendizado e decorrentes da realização de uma tarefa. A tarefa e seus passos estruturam-se em torno de determinado conceito científico a ser aprendido.

A realização do experimento didático, segundo Aquino (2014), ocorre em quatro etapas. Essas, ao nosso ver, não são estanques, pois essa possibilidade contraria a perspectiva teórica adotada, uma vez que ela é dialética, portanto inclui o movimento e contradições. As quatro etapas são: a revisão da literatura e diagnóstico da realidade a ser estudada; elaboração do

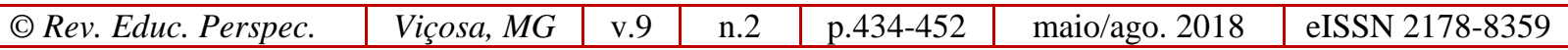


sistema didático experimental; desenvolvimento do experimento didático e análise dos dados; e elaboração do relatório.

A pesquisa, cujos resultados são parcialmente apresentados neste relato de experiência, utilizou a metodologia do experimento didático, considerando-o uma intervenção pedagógica, que busca desenvolver atividades que, por meio dos conhecimentos teóricos, favorecem a aprendizagem e o desenvolvimento de funções psíquicas dos alunos, partindo do pressuposto de que, primeiro, essas são compartilhadas entre os sujeitos (interpsíquicas) e, posteriormente, internalizadas (intrapsíquicas).

Como elemento mediador introduzido no sistema didático e utilizado em todas as atividades, tomou-se o smartphone, pois a pretensão foi usar um recurso, que é bem familiar ao aluno e carregado de apelo social, para auxiliá-lo na solução de tarefas de estudo. De acordo com o conceito de mediação, proposto por Vigotski (2007), a compreensão dos processos mentais implica considerar os instrumentos e os signos como elementos organizadores desses processos. Embora distintos, instrumentos e signos "[...] estão mutuamente ligados [...] na função mediadora que os caracteriza” (VIGOTSKI, 2007, p. 53).

Os dispositivos móveis são equipamentos eletrônicos que permitem realizar atividades em diferentes lugares, ou seja, não necessitam ficar fixos em um único local para se ter acesso aos recursos da máquina. Os principais dispositivos móveis são: notebooks, netbooks, tablets, smartphones, e-readers, entre outros. Eles permitem que as pessoas façam em qualquer lugar muitas atividades que só fariam em casa e no escritório. Mas os dispositivos móveis possuem também diversos recursos que podem ser utilizados sem o uso de rede, especialmente os smartphones. Alguns recursos estão presentes na maioria dos smartphones, tais como: calculadora, calendário, agenda, câmera, áudio, gravador de voz, dicionário, editor de vídeo, relógio/cronômetro, jogos, dentre vários outros recursos de hardware e software. Neste trabalho, concentrou-se a atenção no smartphone, por ser o dispositivo mais utilizado, de menor custo e mais acessível principalmente entre os adolescentes e jovens, com a vantagem, ainda, de não precisar de nenhum custo adicional ou de investimentos em infraestrutura ou treinamento/capacitação dos alunos, pois os jovens têm domínio do uso dos dispositivos móveis, tais como os smartphones. Esses aparelhos fazem parte do dia a dia da maioria deles.

Entretanto, numa perspectiva materialista dialética, não se pode perceber a tecnologia de forma autônoma em relação à dinâmica social, pois o seu uso na educação exige o pensar sobre as relações recíprocas entre os sujeitos sociais e os objetos técnicos. Fundamentando-se em Peixoto (2011), pode-se afirmar que ele é um artefato criado pelo homem, mas cujo significado não se esgota no aparelho que se coloca ao sujeito para o uso de forma autônoma, porque inclui, também, os esquemas de utilização, que são elaborados pelo próprio sujeito ou

\begin{tabular}{l|c|c|c|c|c|c} 
(C) Rev. Educ. Perspec. & Viçosa, $M G$ & v.9 & n.2 & p.434-452 & maio/ago. 2018 & eISSN 2178-8359 \\
\hline
\end{tabular}


apropriados de esquemas sociais de utilização. É essa a concepção que guiou a utilização do smartphone como recurso pedagógico para o ensino e a aprendizagem neste experimento. É importante, ainda, fazer a distinção entre as dimensões material e simbólica do artefato, tendo em vista que ele não se reduz ao objeto técnico ou à máquina. Há que considerar o seu valor simbólico, histórico e social na vida do indivíduo.

Tem-se aqui no smartphone um importante artefato para desenvolver atividades coletivas entre os alunos adolescentes, pois, como se considera na Teoria Histórico-Cultural, nessa etapa do desenvolvimento a atividade guia é justamente a comunicação e as relações sociais afetivas. O smartphone já faz parte do contexto social dos adolescentes e está dotado de grande simbolismo, portanto pode ser um instrumento mediador da atividade, valioso.

Essas atividades tinham o objetivo de desenvolver os conceitos e procedimentos na disciplina Organização Montagem e Manutenção de Computadores, usando o smartphone. A referida disciplina tem como objetivo geral desenvolver as competências necessárias para o aluno desempenhar a função de técnico em manutenção e suporte em informática, conhecendo os conceitos teóricos e as práticas de manutenção e suporte em informática. Na disciplina em questão, o aluno aprende a trabalhar com computadores, impressoras, tablets, smartphones, rede de computadores, etc., desenvolvendo diversas atividades, tais como: montagem e desmontagem de computadores, manutenção preventiva e corretiva de hardware e software, instalação e configuração de sistemas operacionais, solução de problemas, atendimento ao cliente, entre outras. Muitas dessas atividades trazem consigo certo grau de dificuldade de aprendizagem, seja por pouco tempo para serem ensinadas, falta de conhecimento prévio do aluno ou principalmente complexidade dos conteúdos técnicos e técnicas operacionais de execução das tarefas, ou mesmo uma organização do ensino que não conduz a um aprendizado eficaz.

Foram sujeitos do estudo quatorze alunos do $2^{\circ}$ ano do curso referido anteriormente, um dos subgrupos em que a turma era dividida para aulas práticas. Os participantes foram incluídos de acordo com a concordância em participar da pesquisa, alunos com maior dificuldade de aprendizagem, bem como os que possuíam smartphone. O pesquisador foi também o condutor das atividades em sala de aula, acompanhado de um auxiliar para ajudar no posicionamento dos equipamentos e nas observações.

A pesquisa foi submetida ao Comitê de Ética em Pesquisa da universidade à qual os pesquisadores se vinculavam e foi aprovada por atender às exigências éticas para a pesquisa com seres humanos. O Termo de Consentimento Livre e Esclarecido (TCLE) foi assinado pelos responsáveis ou pelos próprios alunos, quando maiores de idade, e o Termo de Assentimento pelos menores, após autorização dos responsáveis.

\begin{tabular}{l|c|c|c|c|c|c} 
(C) Rev. Educ. Perspec. & Viçosa, $M G$ & v.9 & n.2 & p.434-452 & maio/ago. 2018 & eISSN 2178-8359 \\
\hline
\end{tabular}


A análise se realizou tendo em vista um conjunto de "unidades de análise", pois, segundo Vigotski (1996), as unidades permitem conhecer o todo, já que contêm aspectos essenciais desse todo. Foram definidas com base no referencial teórico e nas evidências de aprendizagem e de desenvolvimento psíquico, bem como nas relações entre os envolvidos São elas: a) condições objetivas de realização do experimento; b) apropriação dos conceitos e processos; c) socialização, compartilhamento, construção coletiva e interações; d) autorregulação e autoavaliação; e) contribuições do smartphone para organização do ensino e da aprendizagem.

Essas evidências apareceram nas falas dos alunos e dos professores, nos comportamentos dos sujeitos da pesquisa, nos registros que foram feitos sobre as condições em que se realizou o processo de aprendizagem, nas atitudes, hábitos, habilidades e valores manifestados pelos participantes, nas produções realizadas por eles. Esse trabalho com indícios encontra as suas raízes em Vigotski (1996), ao afirmar que a observação científica sai dos limites do visível e busca os seus significados.

\section{EXPERIMENTO DIDÁTICO: A ATIVIDADE DE ESTUDO VIDEOAULA SOBRE DUAL BOOT}

$\mathrm{Na}$ pesquisa realizada, o experimento didático consistiu de quatro atividades de estudo devidamente organizadas, com base no referencial teórico da Teoria da Atividade de Estudo. Neste relato de experiência, apresenta-se a primeira atividade de estudo, "Videoaula sobre Dual Boot”.

A primeira preocupação no planejamento da atividade estava relacionada com as questões: Como criar uma necessidade de aprendizagem desses conteúdos? Qual seria a motivação para os alunos estudarem e trabalharem com esses conteúdos? Considerando esses questionamentos e buscando superar esses desafios, planejou-se a atividade de estudo de modo que o aluno tivesse que realizar os processos e também explicar o que estava fazendo, tornando-se, assim, sujeito de sua própria atividade. Pensou-se, então, na criação da videoaula, pois dessa forma o aluno seria autor do seu trabalho, a partir de uma necessidade.

A criação do vídeo foi realizada pelos alunos, utilizando a câmera do smartphone para gravar as imagens, a fim de documentar e orientar os passos corretos, seguros e recomendados para a instalação dos sistemas operacionais Windows 7 e Ubuntu 14.04 em dual boot, ou seja, instalar os dois sistemas operacionais no mesmo disco rígido do computador. O objetivo dessa atividade era que os alunos assimilassem os principais conceitos e técnicas gerais que envolvem sistemas operacionais para computadores, tais como: instalação dos sistemas

\begin{tabular}{l|c|c|c|c|c|c} 
(C) Rev. Educ. Perspec. & Viçosa, $M G$ & v.9 & n.2 & p.434-452 & maio/ago. 2018 & eISSN 2178-8359 \\
\hline
\end{tabular}


operacionais, sistema de arquivos, divisão do disco rígido para receber dois sistemas operacionais e configurações básicas de sistemas e usuários. Lembrando que esta é uma das principais tarefas que são realizadas por um técnico em manutenção e suporte em informática.

A atividade foi planejada considerando seus componentes essenciais, pois, conforme Libâneo e Freitas (2015, p. 343), "a atividade está sempre dirigida à criação ou transformação de algum produto material ou espiritual, o que implica compreender claramente qual é o conteúdo objetivo e os componentes de cada atividade humana específica". Seguindo o exposto acima, procurou-se identificar e detalhar no diagrama (Figura 1), os componentes da atividade de estudo, conforme apresentados por Davydov (1999): necessidade, motivos, objetivos, objeto, meios, ações, operações, condições e produto. 


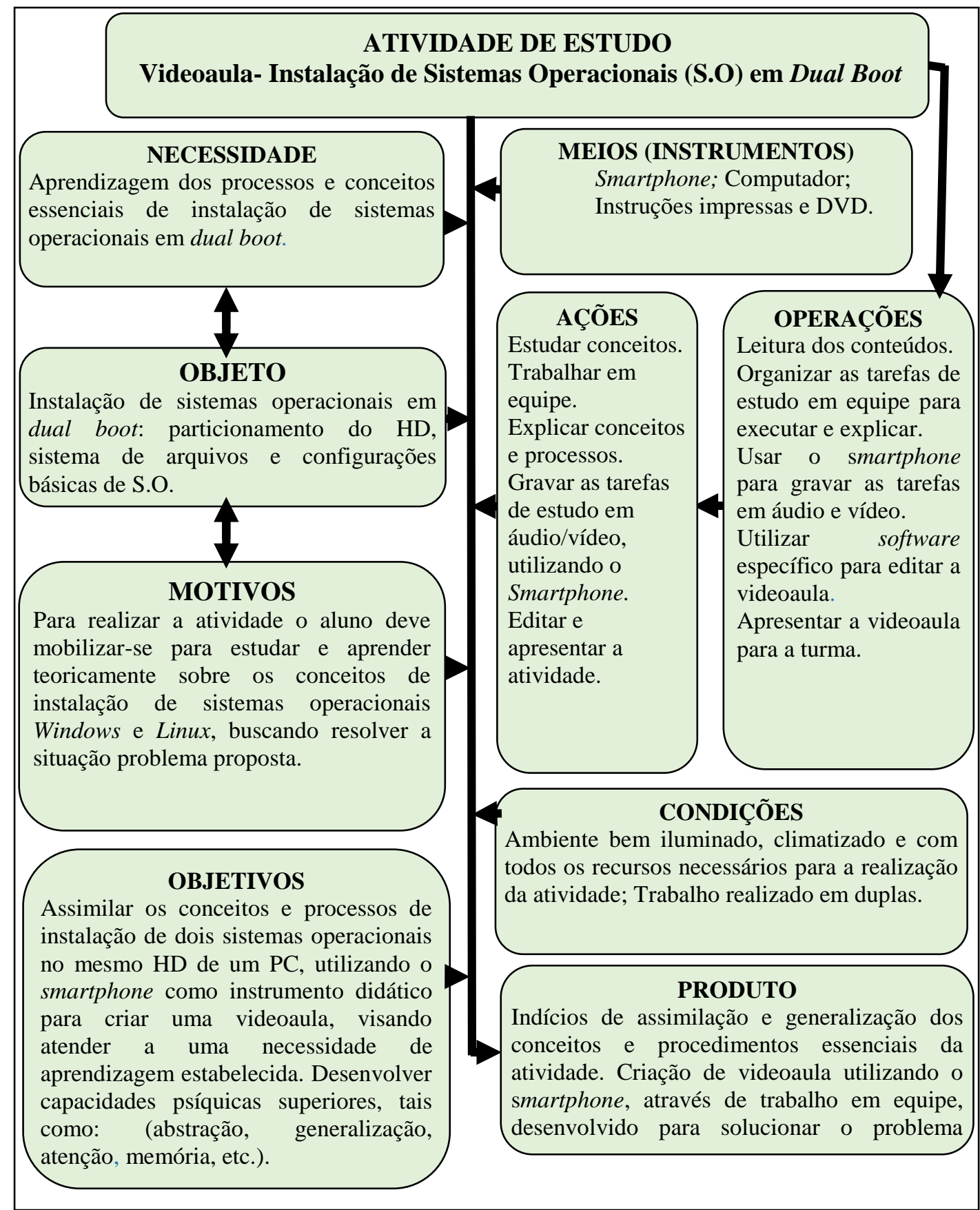

Figura 1. Diagrama d $a$ Atividade de Estudo: Videoaula Fonte: elaborado pelos pesquisadores

No planejamento, foi previsto que toda a atividade de instalação dos sistemas operacionais deveria ser filmada com os smartphones pelos alunos com destaques para as etapas mais complexas e gerais, tais como: divisão dos discos rígidos (particionamento) do computador, início da instalação dos sistemas operacionais, ordem de instalação, configurações básicas de usuários e sistemas. Ao final, seriam feitos testes para verificação do perfeito funcionamento

\begin{tabular}{l|c|c|c|c|c|c} 
(C) Rev. Educ. Perspec. & Viçosa, $M G$ & v.9 & n.2 & p.434-452 & maio/ago. 2018 & eISSN 2178-8359 \\
\hline
\end{tabular}


da atividade proposta, pois essas etapas consistem na parte essencial da atividade. Como foi dito, anteriormente, os alunos realizariam as atividades seguindo as ações previamente elaboradas e acompanhadas pelo professor, e, durante a execução, eles deveriam explicar o que estavam fazendo.

Após a conclusão da filmagem, os alunos deveriam fazer o processo de edição do vídeo para corrigir e ajustar a qualidade das imagens/áudio, assim como selecionar apenas as etapas essenciais da atividade, e, em seguida, apresentar o trabalho para os colegas de turma. Esse processo de edição propiciaria aos alunos rever o trabalho realizado, permitindo a avaliação dos seus erros e acertos, bem como interagir mais com a atividade, tornando-se sujeitos do processo e produtores de conteúdo.

Em relação às condições objetivas de realização da atividade de estudo, no geral, foram adequadas, porque o laboratório de manutenção é um espaço físico próprio, dispondo de bancadas, computadores, mídias de DVD para instalação dos sistemas e kits de ferramentas para manutenção de computadores e os smartphones dos alunos, além de um número reduzido de alunos.

No que se refere à apropriação dos conceitos e processos, uma das principais unidades de análise, há indícios de assimilação desses conceitos e processos nas produções dos alunos e em suas falas:

Nat $^{2}$ : Detalhe importante é que a instalação do Windows tem que vir antes da instalação do Linux, para evitar problemas na inicialização depois.

Pedro: exatamente.

Neste trecho da videoaula da dupla, pode-se observar a preocupação do aluno em alertar sobre este aspecto, que é essencial para o sucesso da atividade, e que também explica o problema que poderá causar, caso não seja observado o alerta apresentado. No vídeo, na fala do aluno Nat a seguir, é possível constatar tanto a assimilação dos processos, quanto dos conceitos envolvidos:

Nat: agora vem uma parte importante, teremos que escolher a última opção, opção avançada, para ter acesso ao particionamento avançado que o Ubuntu tem. Esse aqui [aponta com o dedo] é o menu de particionamento, bem diferente do Windows 7 [...] nós vamos selecionar a última opção, espaço livre, que o Pedro acabou de selecionar, nós agora vamos dividir ela em uma partição de 20GB. Pedro por favor, digita aí 20480 MB, que é 1024 x 20, esta partição vai ser primária, porque é nela que nós iremos instalar o sistema operacional, o sistema de arquivos vai ser journaling ext4, porque ele é mais eficiente, e o ponto principal de montagem vai ser a raiz [/], que é o local onde a pasta do sistema fica [...].

Nat: é importante que vocês vejam como ficou o particionamento do disco rígido (HD), pois a divisão do seu disco pode ser igual ou semelhante a esta, vai depender 
do tamanho do seu disco rígido e agora é só você selecionar a partição ext4 raiz e instalar o sistema operacional Linux [...].

Nat demonstra domínio dos processos que estão sendo executados e vai destacando e dando orientações importantes para a correta operação das tarefas. Quando o aluno diz: "esta partição vai ser primária, porque é nela que nós iremos instalar o sistema operacional [...]", ele evidencia assimilação dos conceitos essenciais da tarefa, pois na sua explicação pode-se observar a sua ação consciente. Ele faz a tarefa e justifica porque deve ser feito daquela maneira, compartilhando com os colegas os conhecimentos teóricos.

Considera-se, agora, o exemplo de uma dupla que não conseguiu concluir a atividade com sucesso, pois demonstrou dificuldade justamente nesta etapa essencial do trabalho particionamento do disco. Vejamos o que aconteceu:

\footnotetext{
Marcos: criando a primeira partição para Windows 7.

Cairo: de 20GB, você vai multiplicar 20 por mil e (...) quanto?

Marcos: 1024.

Cairo: você vai clicar aqui [silêncio], não, acho que é aqui... vamos ver na folha [instruções fornecidas pelo professor].

Cairo: como tinha dado problema na primeira tentativa, aqui agora já está quase pronto, tem uma partição de 20, outra de 18 [...].

Marcos: essa partição de 18 não está errada, não?

[silêncio... os alunos realizam a tarefa, mas não falam mais nada, demonstrando insegurança na execução dos processos].
}

Os alunos Marcos e Cairo começaram a atividade com entusiasmo, conseguindo realizar as tarefas mais básicas, mas, quando chegaram a uma etapa mais complexa, a divisão do disco rígido no sistema operacional Ubuntu, eles demonstraram dificuldade de compreender os procedimentos corretos da tarefa e, também, não explicaram o que estavam fazendo. Constantemente, recorriam à folha de instrução e perguntavam um para o outro se o que estavam fazendo estava correto. Após finalizarem a tarefa, verificaram que a atividade estava com erro, então recorreram ao professor para saber qual foi o motivo do erro do seu trabalho. A identificação do erro pelo aluno também é importante, pois contribui para que ele possa avaliar suas deficiências de aprendizagem e, em conjunto com o professor, desenvolver estratégias para superarem as dificuldades encontradas. Essa é uma atitude de autorregulação e autoavaliação.

$\mathrm{Na}$ análise da atividade de estudo dessa dupla, foi possível identificar as deficiências e a falta de assimilação dos conceitos essenciais e processos da tarefa. Mas é importante registrar que os alunos demonstraram interesse, empenho e motivação para realizar a atividade de estudo na etapa de instalação dos sistemas operacionais e criação da videoaula com o smartphone. Nas etapas de edição do vídeo e apresentação, deixaram a desejar, talvez em virtude do insucesso na tarefa anterior. Isso mostra que os sentidos aos artefatos são construídos pelos

\begin{tabular}{l|c|c|c|c|c|c|} 
(C) Rev. Educ. Perspec. & Viçosa, $M G$ & v.9 & n.2 & p.434-452 & maio/ago. 2018 & eISSN 2178-8359 \\
\hline
\end{tabular}


sujeitos, não são inerentes a eles. Mostra, também, as contradições existentes nas propostas de estudo, pois a apropriação da atividade, ainda que envolva atividades coletivas, é, também, individual.

Os resultados dessa dupla são muito importantes, porque evidenciam que certos alunos ou grupos de alunos precisam de um tempo maior para a apropriação dos conhecimentos e desenvolvimento das habilidades. Fica claro que a gestão da turma não é idêntica à gestão das diferenças individuais; este fato mostra a relevância do professor como principal mediador dos processos de aprendizagem. Caso o professor não estivesse ciente disso e não atuasse de modo adequado, essa equipe ficaria para trás. Foi possível utilizar o erro como uma oportunidade de aprendizagem, principalmente criando situações em que os alunos pudessem encontrá-los e corrigi-los.

Essa atividade de estudo permitiu observar que a maioria dos alunos demonstrou que assimilou os conceitos essenciais e também os processos práticos de instalação dos sistemas operacionais. Isso ficou evidente nas suas explicações nas videoaulas, na edição dos vídeos, sendo alguns com legendas, detalhando as tarefas, e, também, nas apresentações dos alunos, seja nas suas falas, no comportamento, nas imagens e vídeos produzidos por eles. Das sete duplas, apenas a dupla apresentada nas falas anteriores, Marcos e Cairo, não conseguiu finalizar todas as etapas da atividade.

O uso do smartphone como instrumento para auxiliar nas tarefas de estudo propostas contribuiu tanto na atividade de ensino do professor, quanto na atividade de aprendizagem do aluno. Assim, os dois componentes do instrumento - artefato e esquema -foram associados um ao outro, como considera Peixoto (2011). Essa dependência diz respeito ao status que o artefato ganhou na execução da ação da atividade, ou seja, de acordo com os esquemas de utilização, pois o artefato não é em si mesmo um instrumento. Ele depende do significado que o sujeito atribui a ele de acordo com a finalidade de uso nas suas ações. O smartphone só se transformou em um instrumento de ensino, quando foi utilizado por meio de um esquema de ações, previstas na atividade de estudo.

No que se refere à socialização, compartilhamento, construção coletiva e interações, outra unidade de análise, foi possível observar produtivas relações entre os alunos, o compartilhamento de informações, muita interação e construção coletiva. Sabe-se que, nessa fase de adolescência, os alunos valorizam muito a comunicação e as relações interpessoais e atividades em grupo, conforme Elkonin e colegas evidenciaram sobre as etapas de desenvolvimento, ao afirmarem que: "o período da adolescência constitui-se de intenso desenvolvimento intelectual e das funções psicológicas superiores, sob a base das relações

\begin{tabular}{l|c|c|c|c|c|c} 
(C) Rev. Educ. Perspec. & Viçosa, $M G$ & v.9 & n.2 & p.434-452 & maio/ago. 2018 & eISSN 2178-8359 \\
\hline
\end{tabular}


humanas e de trabalho, e influenciam diretamente na formação da personalidade" (LAZARETTI, 2015, p. 233).

Joaquim: Vamos explicar o processo de particionamento no Windows?

Maycon: Não. Acho que podemos explicar quando formos particionar o disco rígido no Ubuntu.

Joaquim: Ah é mesmo, beleza, então.

Joaquim: Você instala o Windows e eu instalo o Ubuntu.

Maycon: Certo.

No trecho acima, verifica-se a interação entre a dupla, eles organizam a forma de trabalhar e dividem a tarefa, de modo colaborativo, seguindo as orientações passadas pelo professor, lembrando que elas eram gerais, deixando livre para as equipes organizarem suas ações. De modo geral, os alunos desenvolvem as tarefas de forma conjunta, eles alternam entre gravação com o smartphone, execução das ações e explicação dos processos, dos conceitos e das recomendações na instalação, construindo, assim, coletivamente, a atividade de estudo. Esse comportamento foi observado em todas as equipes, e verificaram-se ainda diversas formas de organização da atividade: havia dupla em que um gravava e explicava, enquanto o colega executava as tarefas; outras duplas alternavam a gravação e execução, mas explicavam juntos, sempre com um aluno complementando o outro; em outras, um aluno executava e explicava, enquanto o outro só gravava, e depois invertiam a ordem das tarefas; ainda duplas que mostraram suas imagens pessoais na filmagem e outras que só filmaram a tela do computador, entre outras.

No que respeita à autorregulação e autoavaliação, esses processos ocorreram durante toda a atividade, nos diálogos com os colegas e com o professor. Eis uma situação desse tipo:

Murilo: Já acabamos? Vamos verificar as instruções, olha aqui, no final alterar a ordem de boot.

Rafael: Já alteramos!

Murilo: Acessar o Windows 7 e o Ubuntu para verificar se estão funcionando.

Rafael: Já testamos os dois.

Murilo: Então já terminamos. Professor acabamos aqui.

Em síntese, o experimento didático, desenvolvido com a organização adequada das atividades de ensino, utilizando recursos simples e que estão presentes em quase todos os smartphones: recursos de vídeo e áudio, contribuiu para a aprendizagem e o desenvolvimento dos alunos, tornando-os mais motivados para a apreensão de conceitos e processos ligados à disciplina, que, muitas vezes são, complexos, exigem atenção, memória, abstração e generalização.

Os alunos tiveram de planejar como realizariam a atividade, pois, pelo fato de terem que criar a videoaula, eles discutiram entre si como seriam realizados os procedimentos, qual smartphone utilizar, como iriam gravar, executar e explicar, entre outras. Este aspecto é importante ser observado, pois a atividade tem que ser significativa para o aluno. Aliás, ela só

\begin{tabular}{l|l|l|l|l|l|l} 
() Rev. Educ. Perspec. & Viçosa, $M G$ & v.9 & n.2 & p.434-452 & maio/ago. 2018 & eISSN 2178-8359 \\
\hline
\end{tabular}


se torna de fato uma atividade, se o aluno se apropria dela, do contrário, será apenas uma ação. A colocação de uma situação problema, juntamente com atribuição de autonomia e responsabilidade para o aluno, fez com que ele se sentisse motivado para realizar a tarefa. Outro fato importante é que, para o aluno explicar o que está fazendo, ele primeiro tem de seguir as orientações, analisar, e, posteriormente, pensar para explicar e executar as ações propostas na tarefa, num processo dialético de idas e vindas do concreto ao abstrato, num movimento que caracteriza o processo de apropriação dos conhecimentos, que vai do interpsicológico para o intrapsicológico.

Ao analisar a gravação da atividade e as produções dos alunos, pode-se, então, observar o compromisso com a atividade, a atenção voluntária, a abstração e generalização dos conceitos teóricos e processos, como também a construção coletiva. Esses são elementos que estão no cerne da Teoria da Atividade de Estudo.

Assim, os resultados obtidos foram analisados a partir de unidades definidas de acordo com os fundamentos da Teoria da Atividade de Estudo de Davidov. Considerando que os alunos participantes, em sua maioria, tomaram para si as tarefas, como sujeitos conscientes, pode-se afirmar que, de fato, eles se envolveram em uma atividade de estudo. Além disso, pode-se observar o desenvolvimento do pensamento teórico em torno da aprendizagem dos processos e conceitos essenciais de instalação de sistemas operacionais em dual boot, isto é, demonstraram ser capazes de passar da realização das ações no plano mental à sua realização no plano externo e vice-versa, conforme postula Davydov (1986).

\section{CONSIDERAÇÕES}

Ao se introduzir uma situação problema com o uso do smartphone, como instrumento mediador do processo no contexto da atividade de estudo, a partir dos pressupostos teóricos da Teoria da Atividade de Leontiev e da Teoria da Atividade de Estudo de Davidov, criou-se um campo, no qual esse artefato ganhou novos sentidos, o que permite concordar com Peixoto (2011), quando afirma que o artefato é instituído como instrumento pelo sujeito, no bojo da ação que lhe dá direção, como meio para atingir os fins desejados na atividade.

A organização da atividade de estudo, com base em um referencial teórico consistente evidencia a importância de alguns aspectos que nem sempre são considerados, como a criação de necessidades que possam mobilizar o sujeito para se apropriar da atividade de ensino, transformando-a numa atividade de estudo. A inclusão de situações-problema, que exijam esclarecer as condições de origem dos objetos, descobrir sua essência (núcleo),

\begin{tabular}{l|c|c|c|c|c|c} 
(C) Rev. Educ. Perspec. & Viçosa, $M G$ & v.9 & n.2 & p.434-452 & maio/ago. 2018 & eISSN 2178-8359 \\
\hline
\end{tabular}


realizar o movimento do abstrato para o concreto e vice-versa, conduziu à aprendizagem e ao desenvolvimento.

Retomando o objetivo geral da pesquisa, pode-se afirmar, a partir da análise dos dados, que há indícios de que os alunos desse grupo: apropriaram-se das atividades de ensino de modo que elas passaram a se constituir de fato em atividades de estudo; desenvolveram capacidades psíquicas como a atenção voluntária, a memória, a abstração e a generalização, ao partilhar os conceitos e processos propostos na disciplina, num movimento intrapsíquico com os colegas e o professor, reelaborando-os internamente, num movimento interpsíquico, para depois objetivá-los novamente para o grupo, por exemplo, por meio das videoaulas; apropriaram-se dos conceitos e processos ligados à montagem e manutenção de computadores, isto é, desenvolveram o pensamento teórico; desenvolveram a colaboração nas atividades realizadas nos pequenos grupos e no coletivo; desenvolveram a autonomia. Essas considerações se fundamentam nos pressupostos da Teoria da Atividade de Estudo de Davidov, que, por sua vez, apoia-se na Teoria da Atividade de Leontiev, com ênfase nos principais elementos dessas teorias.

A partir de dificuldades durante a realização do experimento didático, levantam-se algumas sugestões para a realização de outras pesquisas, com esse mesmo delineamento, como: definir bem o período em que ocorrerão as atividades, evitando pausas e interrupções do trabalho, e, se possível, disponibilizar uma carga horária maior; verificar se as atividades serão realizadas somente no horário das aulas ou se precisará de complementação em outros momentos e espaços; utilizar pelo menos duas câmeras de filmagem e verificar o seu posicionamento na sala; definir as unidades de análises previamente, ou seja, antes de iniciar o experimento, complementando-as com as que emergirem dos dados empíricos.

Assim, pode-se inferir que o experimento didático se constituiu em um espaço propício para analisar as possibilidades pedagógicas da organização da atividade de estudo como proposta por Davidov, como também analisar formas de uso desse artefato, tão presente na vida das pessoas, principalmente na dos jovens, que é o smartphone.

\section{REFERÊNCIAS}

AQUINO, Orlando Fernández. Leonid Vladimirovitch Zankov: contribuições para a pesquisa em didática desenvolvimental. In: LONGAREZI, Andrea Maturano; PUENTES, Roberto Valdés (Org.). Ensino Desenvolvimental: vida, pensamento e obra dos principais representantes russos. 2. ed. Uberlândia, MG: EDUFU, 2015. P. 245-274. 
AQUINO, Orlando Fernández. O experimento didático-formativo: contribuições para a pesquisa em didática desenvolvimental. XVII Encontro Nacional de Prática de Ensino ENDIPE: Didática e Prática de Ensino na relação com a Formação de Professores. Fortaleza: CE: EdUECE, 2014. P. 04645- 04657 (E-book 2). Disponível em:

<http://www.uece.br/endipe2014/ebooks/livro2/>. Acesso em: 14 abr. 2018.

DAVYDOV, Vasily Vasilovich. O que é a atividade de estudo. Escola Inicial, São Paulo, n. 7, p. 1-9, 1999.

DAVYDOV, Vasily Vasilovich. Problemas do ensino desenvolvimental: a experiência da pesquisa teórica e experimental na psicologia. Textos publicados na Revista Soviet Education, v. 30, n. 8, August, 1986. Trad. José Carlos Libâneo e Raquel Aparecida Marra da Madeira Freitas [Trabalho não publicado].

FREITAS, Raquel Aparecida Marra da Madeira. Pesquisa em Didática: o experimento didático formativo. In: X ENCONTRO DE PESQUISA EM EDUCAÇÃO DA ANPED CENTRO-OESTE: desafios da produção e divulgação do conhecimento, 2010, Uberlândia. Anais... Uberlândia, 2010. P. 1-11.

IDC. Após dois anos, mercado de smartphones cresce em 2017 e atinge o segundo melhor desempenho de vendas. São Paulo, 26 de março de 2018. 2018. Disponível em: <http://br.idclatin.com/releases/news.aspx?id=2312>. Acesso em: 20 jun. 2018.

LAZARETTI, Lucinéia Maria. Daniil Borisovich Elkonin: a vida e as produções de um estudioso do desenvolvimento humano. In: LONGAREZI, Andrea Maturano, PUENTES, Roberto Valdés (Orgs.). Ensino Desenvolvimental: vida, pensamento e obra dos principais representantes russos. 2. ed. Uberlândia, MG: EDUFU, 2015. P. 217-244.

LEONTIEV, Alexei Nikolaevich. O desenvolvimento do psiquismo. Lisboa, Horizonte Universitário, 1978. 356p.

LIBÂNEO, José Carlos; FREITAS, Raquel Aparecida Marra da Madeira. Vasily Vasilyevich Davydov: a escola e a formação do pensamento teórico-científico. In: LONGAREZI, Andrea Maturano; PUENTES, Roberto Valdés (Org.). Ensino Desenvolvimental: vida, pensamento e obra dos principais representantes russos. 2 ed. Uberlândia, MG: EDUFU, 2015. P. $327-$ 362.

LONGAREZI, Andrea Maturano; FRANCO, Patrícia Lopes Jorge. A. N. Leontiev: a vida e a obra do psicólogo da atividade. In: LONGAREZI, Andrea Maturano; PUENTES, Roberto Valdés (Orgs.). Ensino Desenvolvimental: vida, pensamento e obra dos principais representantes russos. 2 ed. Uberlândia, MG: EDUFU, 2015. P. 79-122.

PEIXOTO, Joana. Tecnologias e práticas pedagógicas: as TIC como instrumento de mediação. In. LIBÂNEO, José Carlos; SUANNO, Marilza Vanessa Rosa (Orgs.) Didática e escola em uma sociedade complexa. Goiânia, GO: CEPED, 2011. P. 97-111.

\begin{tabular}{|c|c|c|c|c|c|c|}
\hline (C) Rev. Educ. Perspec. & Viçosa, $M G$ & v.9 & n. 2 & p.434-452 & maio/ago. 2018 & eISSN 2178-8359 \\
\hline
\end{tabular}


REPKIN, Vladimir. Ensino desenvolvente e atividade de estudo. Ensino em Re-Vista, Uberlândia, MG, v. 21, n.1, p. 85-99, jan./jun. 2014. Disponível em: <http://www.seer.ufu.br/index.php/emrevista/article/viewFile/25054/13891>. Acesso em: 14 abr. 2018.

OCDE. Organização para a Cooperação e Desenvolvimento Econômico. Relatório Education at a Glance (EAG). 2016. Disponível em:

<http://www.oecd.org/education/education-at-a-glance/>. Acesso em: 20 jun. 2018.

RIGON, Algacir José; ASBAHR, Flávia da Silva Ferreira; MORETTI, Vanessa Dias. Sobre o processo de humanização. In: MOURA, Manoel Oriosvaldo de (Org.). A atividade pedagógica na teoria Histórico-Cultural. Brasília, Liber livro, 2010. P. 13-44.

VIGOTSKI, Lev Semionovitch. O significado Histórico da Crise da Psicologia: uma investigação metodológica. In: VIGOTSKI, Lev Semionovitch (Org.). Teoria e método em psicologia. São Paulo, Martins Fontes, 1996. P. 203-477.

VIGOTSKI, Lev Semionovitch. A formação social da mente: o desenvolvimento dos processos psicológicos superiores. Trad. José Cipolla Neto, Luis Silveira Menna Barreto e Solange Castro Afeche.7. ed. São Paulo: Martins Fontes, 2007.

\section{NOTAS}

${ }^{1}$ Os autores optaram pelas grafias Davidov e Vigotski para se referirem a Vasily V. Davydov e Lev S. Vygotsky, respectivamente, uma vez que na Língua Portuguesa utilizam-se diferentes grafias. Nas citações obedeceram a grafia presente na obra referenciada.

${ }^{2} \mathrm{O}$ nome utilizado trata-se de um código para não identificação dos sujeitos.

\section{SOBRE OS AUTORES}

${ }^{1}$ Elson de Paula - Mestre em Educação pela Universidade de Uberaba. Professor do Instituto Federal do Triângulo Mineiro. E-mail: elson@iftm.edu.br - ORCID: http://orcid.org/0000-0003-0339-5979

${ }^{2}$ Marilene Ribeiro Resende - Doutora em Educação Matemática pela Pontifícia Universidade Católica de São Paulo. Docente pela Universidade de Uberaba. E-mail: marilene.resende@uol.com.br - ORCID: http://orcid.org/0000-0002-6740-1787 